\title{
Zwischen den Welten - Antike Kulturlandschaften im Illyricum
}

\author{
Anto Pavić
}

Das Wissen um eine antike Kultur ist nicht selten vom Stand der modernen Forschung geprägt. Auf dem Gebiet der Erforschung des antiken Westbalkan hat dieser keineswegs ein Optimum erreicht. Vielmehr haben der politische Umbruch in Osteuropa sowie die Kriege seit den 1990er Jahren in den Nachfolgestaaten des ehemaligen Jugoslawien ein negatives Licht auf jene Länder und seine Menschen geworfen. Diese Bewertung wird darüber hinaus bis in die heutigen Tage paradoxerweise auch auf die Kulturen der Antike übertragen. Dabei bildet die Region an der Adria mit ihren archäologischen Denkmälern aus verschiedenen Jahrtausenden der Menschheitsgeschichte eine der ältesten Kulturlandschaften Europas. In kaum einem anderen Teil des Kontinents finden sich Natur und Kultur derart eng beieinander. Die in albanischer, serbischer, kroatischer oder slowenischer Sprache verfassten wissenschaftlichen Abhandlungen sowie die von den Touristenrouten häufig abseits gelegenen Kulturgüter sind darüber hinaus in Westeuropa zumeist unbekannt. Aus diesem Grund soll dieser Aufsatz einen Beitrag zum kulturellen „Wiederaufbau“ des am Adriatischen Meer und im Dinarischen Gebirge gelegenen antiken Illyricum leisten.

Zunächst wird zur allgemeinen Orientierung der geographische Rahmen abgesteckt. Des weiteren soll die geographische sowie topographische Situation der verschiedenen Kulturlandschaften entlang der Adria sowie des Dinarischen Hinterlandes exemplarisch aufgezeigt werden. Schließlich wird versucht, die sowohl historische als auch archäologische „Lücke“ zwischen Griechenland und Italien für die vorrömische Zeit zu schließen.

\section{Geographischer Rahmen}

Das antike Illyricum befindet sich in Südosteuropa, genauer auf der Balkanhalbinsel, welche allgemein im Süden in den griechischen, im Nordosten in den thrakischen und im Nordwesten in den illyrischen Kulturraum unterteilt wird. Der durch das Adriatische Meer von der Apenninhalbinsel getrennte Westbalkan gliedert sich wiederum in einen schmalen Küstenstreifen mit über tausend davor gelagerten Inseln sowie dem sich daran anschließenden und parallel verlaufenden Dinarischen Gebirge mit Gipfeln von bis zu 2700 Metern Höhe. Dieses ist reich an Erzen und Edelmetallen, von denen nach A. ŠKEGRO ${ }^{1}$ bereits seit prähistorischer Zeit Kupfer, Gold, Silber und Eisen bis in die heutigen Tage abgebaut werden. Darüber hinaus zählen die fruchtbaren Böden des mediterranen Küstenstreifens sowie der ausgedehnten Hochebenen (sogenannten Polje) im Gebirge und auf den Inseln zum natürlichen Reichtum seiner Bewohner. Abgeschlossen wird das gesamte Gebiet im Norden durch die weite Landschaft der Pannonischen Tiefebene.

\section{Histrien}

Im italienischen Sprachraum wird die seit der Bronzezeit auftretende Kultur im nordwestlichen Italien sowie im slowenischen und kroatischen Teil Istriens cultura dei castellieri genannt. Wie bereits F. SEMI ${ }^{2}$ erkannte, unterscheiden sich die castellieri mit kreisrunden und ovalen Grundrissen von denjenigen mit rechtwinkligen

\footnotetext{
${ }^{1}$ ŠKEGRO 2000, 53-55.

${ }^{2}$ SEMI 1991, Tav. 24.
} 
Grundrissen. Der Siedlungsform entsprechend bildet das Gebiet südlich der Julischen Alpen im Flusstal der Vipava demnach die nördliche Grenze der Verbreitung von Gradina-Anlagen (monumentale Bauwerke auf Anhöhen mit einer oder mehreren Ringmauern aus großen Steinblöcken). Sowohl nach der Siedlungsweise auf Anhöhen als auch nach dem Material der Bauwerke aus Stein zu urteilen, unterscheiden sich ebenso die früheisenzeitlichen Kulturgruppen Notranjska ${ }^{3}$ (Innerkrain) im Hinterland von Triest, Dolenjsko ${ }^{4}$ (Unterkrain) in Südostslowenien sowie die Gruppe Sv. Lucija ${ }^{5}$ bzw. Soča im Tal des gleichnamigen Flusses in Westslowenien bereits sehr früh von den Siedlungen im benachbarten Südostalpenraum und dem venetischen Raum. Aus den beweglichen Funden ist zu schließen, dass die oben genannten Gruppen seit ihrem Auftauchen in der frühen Eisenzeit eigenständige Ethnien bilden und daher zurecht nicht mit den ,illyrischen“6 Kulturen vergleichbar sind. Der Siedlungsweise auf Grundlage von Gradina-Anlagen zufolge kann die Region bis zur keltischen Einwanderung im 4. Jh. v. Chr. jedoch zum nordwestlichsten Ausläufer der an der Ostadria sowie in den Dinariden gelegenen Gradina-Zivilisation gezählt werden.

Während im Westen und Süden das Adriatische Meer die Halbinsel umgibt, bestimmen im östlichen Teil Istriens der Fluss Arsia (Raša) sowie das ĆićarijaGebirge die natürliche Abgrenzung zu Liburnien und Japodien. Die zur West- und Südküste hin sanft abfallende und durch eine große Anzahl von Flüssen und Bächen durchzogene Hügellandschaft mit fruchtbaren Böden bietet, dem archäologischen Befund nach zu urteilen, seit dem Beginn der frühen Bronzezeit auf den Kuppen den Ort für Gradina-Anlagen.

Auf der Halbinsel Istrien sind bislang 350 castellieri / gradine gezählt worden ${ }^{7}$, wovon 47 Gradinen wiederum alleine im Hinterland von Ruginium (Rovinj) lokalisiert und dokumentiert worden sind. ${ }^{8}$ Wie auf dem gesamten Westbalkan, ist auch für Histrien eine große Anzahl neuer befestigter Anlagen nachgewiesen, die in die Zeit des Übergangs vom zweiten zum ersten vorchristlichen Jahrtausend datiert werden können. Demnach stellt die histrische Landschaft bis zur römischen Eroberung die am dichtesten besiedelte Region entlang der adriatischen Ostküste dar. ${ }^{9}$

Die auf Inseln, Halbinseln und Bergrücken gelegenen histrischen GradinaAnlagen besitzen einen oder mehrere Ringe mit vier bis fünf Meter starken Mauern aus großen Steinblöcken. Die Straßen wurden in konzentrischen Kreisen entlang der Höhenlinien angelegt, während der Niveauunterschied über Treppen geregelt wurde (z.B. Pola, Ruginium, Orsera). Charakteristisch für Höhensiedlungen in Histrien ist darüber hinaus die Anlage auf zwei oder drei Hügeln (z.B. Mordele, Picugi). ${ }^{10}$

Wie bei den anderen ostadriatischen Gemeinwesen unterstanden nach B. KunTIĆ MAKVIĆ ${ }^{11}$ meist mehrere kleinere einer führenden größeren Siedlung, deren gesamte Gemeinde durch eine Vielzahl von Wallburgen geschützt wurde. Jedoch werden von Livius (XLI 2, 4-16) für das 3. / 2. Jh. v. Chr. lediglich drei Orte der

\footnotetext{
${ }^{3}$ Vgl. GABROVEC 1987a, 151-177.

${ }^{4}$ GABROVEC 1987c, 29-119; DULAR - TECCO HVALA 2007.

${ }^{5}$ GABROVEC 1987b, 120-150.

${ }^{6}$ In diesem Fall ist ,illyrisch“ als allgemeiner Sammelbegriff für die verschiedenen ostadriatischen oder westbalkanischen Kulturen, Landschaften sowie ethnischen Gruppen gemeint und nicht mit dem Ethnos-Begriff zu verwechseln, welcher der von PARZINGER 1991 gelösten Illyrer-Frage eindeutig der Gruppe Glasinac-Burrel zugeschrieben wurde.

${ }^{7}$ Vgl. MARCHESETTI 2003; MIHOVILIĆ 2005a, 31.

${ }^{8}$ BEKIĆ 1996, 19-92.

${ }^{9}$ Vgl. GABROVEC - MIHOVILIĆ 1987, 293-338; STARAC 1999, 11-15; MIHOVILIĆ 2005b, 38-62.

${ }^{10}$ Vgl. WILKES 1992, 63.

${ }^{11}$ KUNTIĆ MAKVIĆ 2007, 22.
} 
Histrier als Oppida bezeichnet und damit gegenüber der Vielzahl weiterer Siedlungen wohl ihr urbaner Charakter unterstrichen. Demnach heben sich die Städte Nesactium, Mutilla sowie Faveria deutlich von den größeren Hauptorten mit ihren lediglich protourbanen Strukturen ab. Das im südlichen Istrien gelegene Nesactium war nach Livius die Hauptstadt des ab dem 2. vorchristlichen Jahrhundert in antiken Quellen als Königreich bekannten Landes (Livius XLI 11,1; Strabon V 1,9; VII 5,3; Plinius, NH III 129). Daneben sind auf bzw. in der Nähe von Gradina-Anlagen in römischer Zeit weitere urbane Zentren entstanden. Zu diesen zählen nach A. STARAC ${ }^{12}$ Tergeste, Castellum Pucinum, Aegida, Neapolis, Piquent, Petena, Parentium sowie Pola.

Darüber hinaus war Histrien bereits seit der frühen Bronzezeit eine Kontaktzone zwischen den Kulturen Mitteleuropas einerseits und den Hochkulturen des östlichen Mittelmeerraums andererseits, was sowohl Bernsteinfunde von der Ostsee als auch Keramik aus Kreta und Zypern belegen. ${ }^{13}$ Im ersten vorchristlichen Jahrtausend hingegen ist ein intensiver Handelskontakt mit Apulien (11.-7. Jh. v. Chr.) ${ }^{14}$ sowie mit Etrurien (8.-4. Jh. v. Chr.) ${ }^{15}$ archäologisch belegt, der nicht zuletzt auf die geographische Lage der histrischen Gemeinwesen zurückzuführen ist. ${ }^{16}$

\section{Liburnien}

Im Gegensatz zur histrischen Landschaft setzt sich der Lebensraum der Liburner ${ }^{17}$ zunächst aus dem Küstenstreifen vom östlichen Teil der Halbinsel Istrien mit dem Fluss Arsia (Raša) sowie dem Učka-Gebirge als natürlicher Grenze im Nordwesten bis zum tief in das Land einschneidenden Canyon des Flusses Tedanius (Krka) im Südosten an der Grenze zu den Delmatern zusammen. Eine Vielzahl vorgelagerter Inseln unterschiedlicher Größe, von welchen einige in der griechischen Mythologie Erwähnung finden (Apsyrtides, Mentorides, Elektrides), bildeten sowohl weitere Siedlungsgebiete als auch Acker- und Weideflächen. Gegenüber den östlich der Liburner siedelnden Japoden bildeten die Bergketten Gorski Kotar und Velebit nicht nur eine ethnische und politische Grenze, sondern auch eine Klimabarriere zwischen dem mediterranen Klima an der Küste und dem kontinentalen Klima des Landesinneren.

Am Übergang zur Eisenzeit, noch bevor Rom gegründet worden war und in Etrurien die ersten ebenfalls auf Bergrücken entstandenen Siedlungen befestigt wurden, befand sich die „Liburnische Thalassokratie“ (Hekataios FGrH I F 93; Strabon VI 2,4) bereits auf ihrem Höhepunkt (Abb. 1). Während zeitgleich vom früharchaischen Griechenland sowie von Phönizien aus die Kolonisation des westlichen Mittelmeerraums verfolgt wurde, beherrschten die Liburner den antiken Quellen zufolge (Strabon VIII 5,2; Florus, Epitome I 21; Appian, Illyr. II 39; Plinius, NH III 112) einen Großteil des Adriatischen Meeres bis nach Korfu im Ionischen Meer und hatten Kontakte sowohl nach Griechenland und Sizilien als auch zu Nachbarvölkern wie Japoden und Delmatern. Auf der gegenüberliegenden italischen Küste hatten die Liburner vor allem zu Apulien, Daunien und Picenum Verbindungen, wo einige Handelsniederlassungen und sogar Siedlungen wie z. B. Truentum Liburnorum (Plinius, NH III 110) gegründet wurden. ${ }^{18}$

\footnotetext{
12 STARAC 1999, 107-139.

${ }^{13}$ MIHOVILIĆ 2005a, 33-34.

${ }^{14}$ MILIČEVIĆ BRADAČ 2007, 38.

${ }^{15}$ GIRARDI-JURKIĆ 1988, 22-28.

${ }^{16}$ DŽINO 2005, 53.

${ }^{17}$ Vgl. BATOVIĆ 1987, 339-390; STARAC 2000, 7-22.

${ }^{18}$ ČAČE 1983-84, 7-16.
} 
Das Kerngebiet der liburnischen Expansion befand sich allerdings in der fruchtbaren Tiefebene der „Ravni Kotari“ im unmittelbaren Hinterland von Zadar. Dort sind mehrere größere sowie kleinere befestigte Siedlungen aus dieser Zeit bekannt. Es handelt sich dabei um Höhensiedlungen auf weit voneinander verstreut liegenden einzelnen Hügeln oder vorgelagerten Bergrücken von mehreren hundert Metern Höhe, welche in die teils fruchtbare, teils karstige Flachlandschaft eingebettet sind. Im Gegensatz zu den histrischen Siedlungen mit mehreren Mauerringen besitzen die liburnischen Orte aufgrund der steil abfallenden Anhöhen zumeist nur eine Umfassungsmauer. Die Mauerstärken von 10 m (Gračišće bei Labin), 15 m (Zelića gradina in Žegar) und $30 \mathrm{~m}$ (Burnum) finden sich alle im liburnischen Grenzgebiet zu den Landschaften Histrien, Japodien und Delmatien.

Laut A. STARAC ${ }^{19}$ verfügt die antike Landschaft Liburnien vermutlich über insgesamt zwischen 500 und 800 Gradina-Anlagen. Darüber hinaus kamen nach J. CHAPMAN und R. SHIEL ${ }^{20}$ in Bezug auf die Siedlungsstruktur, die am Beispiel der Ravni Kotari ausgeführt wird, zu den verschiedenen Höhensiedlungen sogenannte Flachlandsiedlungen (lowland farms) mit Kleinvieh- und landwirtschaftlichem Faktor hinzu. Demnach bestand ein liburnisches Gemeinwesen in der Regel aus einem flächenmäßig großen, mit Megalithen umfassten Zentralort, mehreren kleinen ebenfalls befestigten Siedlungen und schließlich flächenmäßig nochmals kleineren unbefestigten Siedlungen bzw. agrar- und kleinviehwirtschaftlichen Gütern im Flachland. Insbesondere entlang der Küste des liburnischen Kernlandes sowie auf den vorgelagerten Inseln sind zahlreiche Gradinen nachgewiesen und dienten vermutlich als Wallburgen zur Sicherung des Verkehrs von Schiffen und Waren (z.B. auf den Inseln Ugljan, Iž, Pašman, Školj bei Pakoštane). Neben größeren Höhensiedlungen als Zentralorte existieren ebenfalls Hauptorte von Gemeinwesen, die sich sowohl strategisch als auch wirtschaftlich durch eine günstige Lage von Inseln und Halbinseln an der Küste auszeichnen. Im Falle des heute auf einer Insel in einer Bucht unmittelbar vor der Küste gelegenen und mit einer Mauer umgebenen vorrömischen Ortes Aenona ist nach M. SuIĆ ${ }^{21}$ nicht ausgeschlossen, dass sich die Siedlung ursprünglich auf einer Anhöhe befand. Die seit der frühen Kaiserzeit bis heute noch bestehende topographische Situation insgesamt wird durch den seit der Siedlungsgründung im 9. Jh. v. Chr. steigenden Meeresspiegel erklärt.

Mit Blick auf die politischen Verhältnisse wird neuen Erkenntnissen zufolge mittlerweile in Betracht gezogen, dass zwischen den aus römischer Zeit bezeugten einzelnen civitates demnach für die vorrömische Zeit ein Bündnis von Städten zu erkennen ist, wie es bereits für griechische oder etruskische Städte belegt ist ${ }^{22}$. Zu diesem frühen „Städtebündnis“ müssen Asseria, Varvaria, Corinum, Nedinum, Burnum, Alveria, Iadera sowie Aenona gezählt werden. Bei den antiken Autoren sind, wenn auch in späterer Zeit, jeweils zehn, zwölf und vierzehn Städte als Hauptorte der Liburner bekannt, die ihre Zusammengehörigkeit bis in die römische Kaiserzeit im conventus von Scardona bewahrt haben (CIL III 2810; Plinius NH III 139). ${ }^{23}$ Im Jahre 385 v. Chr. (Diodor XV 14, 1; CIG II 1837c) kämpfte ein liburnisches Bündnis gegen Dionysios I., so dass nach S. ČAČ ${ }^{24}$ die Gründung einer Konföderation in Liburnien sich bereits im späten 5 . oder frühen 4 . Jh. v. Chr. vollzogen haben wird. Bis in die

\footnotetext{
${ }^{19}$ STARAC 2000, 11.

${ }^{20}$ CHAPMAN - SHIEL 1991, 66.

${ }^{21}$ SUIĆ $1968,19$.

22 DŽINO 2005, 52; SUIĆ 1981, 107-109; BATOVIĆ 1987, 380-381; KUNTIĆ MAKVIĆ 2007, 25.

${ }^{23} \mathrm{Vgl}$. GLAVIČIĆ - MILETIĆ 2008, 420-421.

${ }^{24} \breve{C} \mathrm{AČE} 1987 / 88,81$.
} 
römische Zeit hinein sind schließlich insgesamt 37 Zentralorte liburnischer GradinaGemeinwesen als Städte (polis, civitas, colonia, municipium) namentlich bekannt. ${ }^{25}$ Demzufolge hat das antike Liburnien neben Südillyrien als die am meisten urbanisierte Landschaft auf dem Westbalkan zu gelten, was auch durch den archäologischen Befund gestützt wird.

\section{Japodien}

Der Siedlungsraum der Japoden ${ }^{26}$ verlagerte sich nach Auskunft der antiken Quellen (Hekataios FGrH 8; Caesar Gall. VIII 24,3; Appian III 18) sowie zahlreicher archäologischer Funde im Laufe der Jahrhunderte, jedoch befand sich ihr Kerngebiet nach B. KUNTIĆ MAKVIĆ ${ }^{27}$ rechtsseitig des Flusses Oenus (Una) sowie in der LikaHochebene und in dem bewaldeten Gebirge des Gorski Kotar. Die Grenze nach Süden gegen die Liburner bildeten das Massiv des mons Baebius (Velebit) sowie der Tedanius flumen (Zrmanja), jedoch dehnte sich diese vor dem 2. Jh. v. Chr. eine Zeit lang auch auf den liburnischen Küstenabschnitt zwischen Istrien und der Zrmanja aus. ${ }^{28}$ Das Bergmassiv der Plješevica bildete eine natürliche Grenze nach Osten gegen die Ditionen, ${ }^{29}$ nach dem 5. Jh. v. Chr. weiteten die Japoden ihren Einflussbereich auch ins Tal der Una um Bihać im westlichen Bosnien aus. ${ }^{30}$ Während im Nordwesten das Ćićarija-Gebirge das Land gegen die Histrier und die alpes Iuliae (Julische Alpen) gegen die venetischen Carni abgrenzte, breitete sich das japodische Siedlungsgebiet im Norden südlich des Oberlaufs der Sava gegen die seit dem 4. Jh. v. Chr. in jenes Gebiet einwandernden keltischen Tauriscer aus. Im Nordosten grenzten die Japoden an die teils bewaldete, teils sumpfige und von den Kolapianen (pannonisches Volk) bewohnte Flusslandschaft. Dieses Gebiet entspricht dem heutigen Pokuplje und Kordun im mittleren Kroatien.

Außer den für den Karst typischen Hochebenen, ist das antike Siedlungsgebiet der Japoden eine sehr bergige sowie stark bewaldete Region, bildete doch gerade der Holzhandel die Wirtschaftskraft dieses Volkes. Daneben betrieben die Japoden eine intensive Viehzucht und Landwirtschaft sowie Metallverarbeitung, Gewerbe und Handel. ${ }^{31}$

Nach B. KUnTIĆ MAKVIĆ waren die Japoden in Territorialgemeinschaften mit Stadtzentren auf Wallburgen in den bergigen Regionen oder in Pfahlbausiedlungen in den Flusstälern sehr gut organisiert und wurde von Präpositen oder Principes verwaltet. Aufgrund mangelnder Forschung lassen sich die Höhensiedlungen bislang „nur“ als geräumig und mit einer Wehrmauer umfasst beschreiben. Über die Infrastruktur der japodischen Siedlungen ist, außer der Erwähnung eines

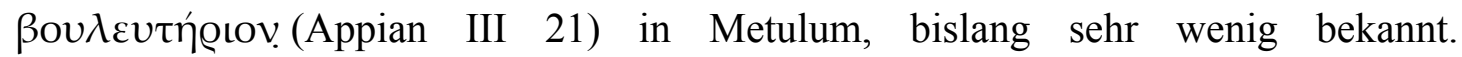
Archäologisch nachweisbar sind steinerne Fundamente von dicht bebauten Gebäuden, welche in einen oder zwei Räume gegliedert sind. Als wichtigste bislang bekannte Siedlungen gelten Metulum, Monetium (Brinje), Avendo (Crkvina bei Brlog / Otočac) und Arupium (Vital bei Prozor), wobei es sich noch nicht um Städte (urbes) gehandelt haben soll. ${ }^{32}$

\footnotetext{
${ }^{25}$ STARAC 2000, 75-109.

${ }^{26}$ Vgl. DRECHSLER-BIŽIĆ 1987, 391-441; OLUJIĆ 2007; BALEN-LETUNIĆ 2004, 211-257.

${ }^{27}$ KUNTIĆ MAKVIĆ 2007, 28-29.

${ }^{28}$ WILKES 1992, 197.

${ }^{29}$ DOMIĆ KUNIĆ 2006, 82.

${ }^{30}$ WILKES 1992, 197; DŽINO 2005, 51.

${ }^{31}$ KUNTIĆ MAKVIĆ 2007, 30.

${ }^{32}$ KUNTIĆ MAKVIĆ 2007, 29.
} 
Darüber hinaus können die Gradina-Anlagen in Japodien auch jeweils zwei Hügel einnehmen. Zudem ist, nach dem archäologischen Befund zu urteilen (z.B. Mali i Veliki Obljaj, Mali i Veliki Vital) ${ }^{33}$, eine große Menge an Erdbewegungen an japodischen Gradinen nachzuweisen. Dabei handelt es sich um Doppelanlagen, deren Zwischenraum künstlich aufgeschüttet wurde, um somit eine größere Siedlungsfläche zu schaffen.

Dem römischen Historiker Appian (III 16, 17, 21) zufolge sind jeweils

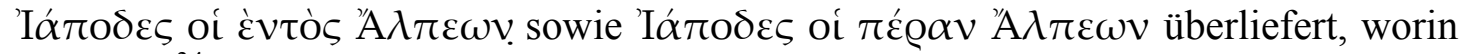
D. DŽINO ${ }^{34}$ einen cisalpinen Bund unter Führung der civitas von Arupium und einen transalpinen Bund unter Führung der civitas von Metulum erkennen möchte. Das sich im Hinterland der nördlichen Adria erstreckende Siedlungsgebiet der Japoden war im Vergleich zu anderen Gemeinwesen demnach in zwei ,protostaatliche“ Gemeinschaften organisiert.

Den archäologischen Funden verschiedener Provenienz nach, gab es Kontakte sowohl zu den Nachbarregionen Histrien, Liburnien und Pannonien als auch über traditionelle Handelswege einerseits durch den strategisch wichtigen Okra-Pass nach Oberitalien und Etrurien, andererseits durch die Anbindung über die Sava-Ebene an die Donau und somit $\mathrm{zu}$ den griechischen Kolonien im östlichen Schwarzmeergebiet. ${ }^{35}$

\section{Delmatien}

Die Delmater ${ }^{36}$ schlossen sich südöstlich der „Liburnischen Konföderation“ im alpinen Hinterland der Mittleren Adria an. Das sowohl in politischer als auch in militärischer Hinsicht bedeutende Volk war seit dem 3. / 2. Jh. v. Chr. in einem Bund von verschiedenen Gradina-Gemeinwesen („,civitates“) unter Führung der civitas von Delmion organisiert. ${ }^{37}$ Zur Zeit der größten Ausdehnung erstreckte sich der „Delmatische Bund“ vom Canyon der Flüsse Tedanius (Krka) im Nordwesten gegen die Liburner, bis zum Urbanus (Vrbas) im Nordosten gegen die Daesitiaten und bis zum Naron (Neretva) im Südosten gegen die Illyrer. Im Südwesten bildete die Küste des Adriatischen Meeres eine natürliche Grenze zur Einflusssphäre des Issäischen Staatenverbundes.

Während der schmale Küstenstreifen mit fruchtbaren Böden gesäumt ist, bietet das karstige Gebirge im Hinterland der Mittleren Adria nur geringe Mengen an agrarisch nutzbarem Land. Vielmehr weist die Region eine seit dem Spätneolithikum kontinuierlich betriebene intensive Kleinviehwirtschaft auf. ${ }^{38}$

Die antiken literarischen Quellen (Strabon VII 5,5; Plinius d.J. III 22; Appian III 11) sprechen ferner auch von Städten der Delmater, worin G. ALFÖLDY ${ }^{39}$ lediglich befestigte Dörfer sehen will. Jedoch konnten spätere Forschungen auch bei diesem Volk komplexe Siedlungsstrukturen mit Gradinen als Sitz der Oberschicht und jeweils mit Ringwällen umgebene Unterstädte nachweisen. Zudem ,erwähnt Strabon (VII 5,5), dass die Delmater 50 Siedlungen bewohnten, von denen Salona als der

\footnotetext{
${ }^{33}$ Vgl. DRECHSLER-BIŽIĆ $1987,76$.

${ }^{34}$ DŽINO 2005, 52.

${ }^{35}$ DOMIĆ KUNIĆ 2006, 63, 68.

${ }^{36}$ Vgl. ČOVIĆ 1987a, 442-480.

${ }^{37}$ DŽIINO 2005, 48.

${ }^{38}$ MLEKUŽ 2007, 4-5.

${ }^{39}$ ALFÖLDY 1965, 197.
} 
delmatische Haupthafen und Pronona, Ninia, Alt-Sinotion, Neu-Andetrion und Delmion als Großstädte hervorgehoben werden“" ${ }^{40}$

Nach J. WILKES ${ }^{41}$ waren die Delmater zweifellos bekannt für ihre Wallburgen bzw. Gradina-Anlagen. Bemerkenswert sei hier, wie im gesamten ostadriatischen Raum, die komplex gegliederte Siedlungsstruktur. Am Beispiel der Gradinen in der Hochebene von Duvno (Duvanjsko polje) lasse sich diese Entwicklung sehr gut verfolgen.

Die auf bis zu 900 Metern Höhe gelegene und ungefähr 20 x 9 Kilometer große Ebene wird von ungefähr 1700 bis 2300 Meter hohen Bergen umschlossen. Am Rande der Hochebene wurden auf den vorgelagerten Bergkuppen 37 derartige Anlagen errichtet. Das Areal mit einigen wenigen Höhensiedlungen aus der Bronzezeit wurde durch zahlreiche weitere Siedlungen sowie durch Wallburgen erweitert, bis schließlich im 3. und 2. Jh. v. Chr. die gesamte Ebene von Gradinen umschlossen und geschützt wurde. In den benachbarten Hochebenen von Livno, Glamoč, Imotski und Buško blato ist dieselbe Entwicklung nachzuweisen. Neben der sowohl architektonischen als auch logistischen Meisterleistung, zahlreiche Bergkuppen zu planieren sowie Befestigungsmauern an schwer zugänglichen Orten $\mathrm{zu}$ errichten, ist die Wahl ihrer strategischen Lage hervorzuheben. Derartige, ein weitläufiges Territorium überblickende Wallburgen waren nicht nur leicht zu verteidigen, vielmehr wurden sie nach einem ausgeklügelten Schema angelegt. Jede Gradina hatte zu einer oder mehreren anderen Gradinen Sichtkontakt, so dass im Falle einer Gefahr von außen nicht nur die jeweilige Gemeinde, sondern die Bewohner eines weitläufigen Gebiets gewarnt werden konnten.

Nach neueren Erkenntnissen war das System von Höhensiedlungen und Wallburgen einer führenden Gradina untergeordnet. Die Gradina-Zentralorte entwickelten sich zu wirtschaftlichen, politischen sowie kulturellen Zentren der jeweiligen Gemeinden. ${ }^{42}$ Wie bereits J. WILKES ${ }^{43}$ erkannte, hatte die Siedlung auf dem Berg Lib im Osten der Hochebene von Duvno eine protourbane Entwicklung erreicht. Dabei handelt es sich wohl um nichts weniger als die Hauptstadt des „Delmatischen Bundes“ mit einer Akropolis und einer Unterstadt auf der darunter liegenden Terrasse.

Kontakte nach außen werden von den antiken Quellen (Polybios XXXII 9, 18; Appian, Illyr. 11-12) nur aus Anlass kriegerischer Auseinandersetzungen mit den Nachbarvölkern (Liburner, Illyrer, Griechen, Römer) überliefert. Obgleich es keine Erz fördernden Bergwerke in Delmatien gab, wurden Waffen und Ausrüstung in metallurgischen Zentren hergestellt. ${ }^{44}$ Dieser Umstand lässt vermuten, dass es zumindest Kontakte zum benachbarten, an Edelmetallen reichen Land der Daesitiaten gab. Allerdings ist bislang nicht bekannt, ob die Delmater sich des begehrten Erzes durch Handel oder Krieg bemächtigten. Als Erscheinung aus der südlich benachbarten Illyris treten in besonderem Maße sogenannte illyrische Helme sowie Rundschilde auf.

Obgleich in Delmatien Funde aus dem mykenischen Kulturraum von Kontakten bereits in der späten Bronzezeit zeugen, gilt seit dem 6. Jh. v. Chr. ein Austausch von Gütern im Küstenbereich zwischen den Gemeinschaften der Hylloi, Boulinoi und Nestoi sowie den davor gelagerten Inseln Brač, Hvar, Vis und Palagruža als gesichert. Dafür sprechen Funde griechischer Provenienz aus dem heutigen

\footnotetext{
${ }^{40}$ KUNTIĆ MAKVIĆ 2007, 27.

${ }^{41}$ WILKES 1992, 190.

${ }^{42}$ KUNTIĆ MAKVIĆ 2007, 22.

43 ŠKEGRO 1999-2000, 398.

44 ŠKEGRO 2000, 56.
} 
Mitteldalmatien wie z. B. Keramik, Kleinplastik aus Terrakotta, Reliefs und Inschriften aus Stein, Goldschmuck, Silber- und Bronzemünzen, Bronzeobjekte sowie Gewichte. Als ein früher Handelsplatz der archaischen Zeit ist unter anderem der Ort des späteren hellenistischen und daraufhin römischen Salona anhand griechischer Funde bezeugt. ${ }^{45}$

Nachweise für Siedlungen aus der frühen und mittleren Bronzezeit sind auf den Inseln bislang nicht bekannt; selbst auf dem Festland ist wenig aus dieser Zeit dokumentiert. In der späten Bronzezeit hingegen ist in Mitteldalmatien eine erstaunliche Zunahme an befestigten Höhensiedlungen zu erkennen, welche auf den Inseln als große, mit Kyklopenmauerwerk versehene Anlagen in der Nähe von fruchtbarem Land zu verzeichnen sind. Noch bedeutender allerdings sind mykenische Keramikfunde auf der Gradina Škrip auf der Insel Brač, welche als ein Beleg für Kontakte zwischen den mitteladriatischen Insel-Gemeinwesen und jenen in Griechenland bereits ab 1300 v. Chr. heranzuziehen sind. ${ }^{46}$

\section{Ostdalmatien (Maezaeer, Ditionen, Daesitiaten)}

Im Dinarischen Gebirge stellt sich die topographische Situation als eine besondere dar. Diese seit dem Neolithikum als Bindeglied zwischen Adria- und Donauraum bedeutende Region ${ }^{47}$ wird einerseits von dicht bewaldeten Bergen sowie zahlreichen tief einschneidenden Flüssen geprägt. Andererseits verfügt das Gebiet, verglichen mit der karstigen Landschaft des südwestlich gelegenen und zur Küste hin auslaufenden Landes der Dinariden, über mehr fruchtbare Böden. Zudem ist das Land sehr reich an Erzvorkommen. Bereits seit dem Neolithikum sind die Förderung von Gold, Silber, Kupfer sowie Eisen nachgewiesen. ${ }^{48}$

Den antiken Quellen sowie dem archäologischen Befund nach zu urteilen, bildete im nordwestlichen Teil des Dinarischen Gebirges das Flusstal der Sana das Kernland der M $\alpha \zeta \alpha$ ĩo / Maezaei. Demnach erstreckte sich dieses im Westen bis zum Oenus (Una) zu den Japoden. Im Osten bildete hingegen der Urbanus (Vrbas) die Grenze zu den $\Delta \alpha \iota \sigma \iota \tau \iota \tilde{\alpha} \tau \alpha \iota /$ Daesitiatae. Während das Land der Mäzäer im Süden bis zu den Gebirgszügen des Grmeč und der Srnetica gegen die Ditionen reichte, bildeten im Norden wahrscheinlich die Ausläufer der Kozara die Grenze zum Land der Osseriaten (pannonisches Volk). Aufgrund des Abbaus der reichen Eisenvorkommen in den Tälern der Sana und Japra werden die Mäzäer von A. DoMIĆ KUNIĆ $^{49}$ als Bergwerksleute und Metallurgen charakterisiert. Als Hauptort der Mäzäer gilt Splonum (Sanski Most), welches bereits in der frühen Eisenzeit überregionalen Charakter erlangte. ${ }^{50}$

Südlich der Gebirgszüge des Grmeč und der Srnetica schließen sich die

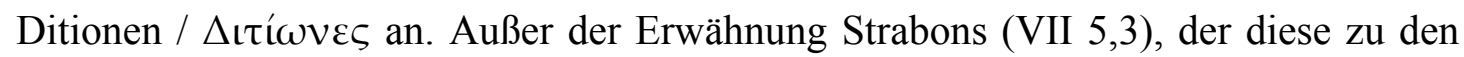
„Pannoniern“ zählt, gibt es aufgrund fehlender Grabungen keine weiterreichenden Kenntnisse über dieses Volk und seine Siedlungsstruktur. Basierend auf den Angaben von SERGEJEVSKIJ ${ }^{51}$ über den unteren Lauf des Unac, schreibt A. DOMIĆ KUNIĆ ${ }^{52}$ den

\footnotetext{
${ }^{45}$ Funde griechischer Provenienz finden sich heute insbesondere in den Archäologischen Museen in Zagreb, Zadar, Split, Trogir sowie in Vis und Starigrad auf Hvar, vgl. KIRIGIN 2003, 27-29; ČARGO 2004, 39-46; KIRIGIN 2008.

${ }^{46}$ GAFFNEY 2001, 137-156.

${ }^{47}$ Vgl. BOARDMAN 1982, 75-186; ČOVIĆ 1976.

${ }^{48}$ Vgl. Anm. 1.

${ }^{49}$ DOMIĆ KUNIĆ 2006, 81.

${ }^{50}$ WILKES 1992, 51, 54.

${ }^{51}$ SERGEJEVSKIJ 1931,23.
} 
Ditionen jedoch 80 kleine Gradina-Siedlungen mit durchschnittlich je 360 Einwohnern zu. Nach diesem Stand ergibt sich für das Land der Ditionen bislang das Bild einer dörflichen Siedlungsstruktur, welches sich durch zukünftige Forschungen im heutigen südwestlichen Bosnien sehr wohl ändern könnte.

Das dritte und bedeutendste Volk in den nördlichen Ausläufern des Dinarischen Gebirges sind die Daesitiatae / $\Delta \alpha \iota \sigma \iota \tau \tilde{\alpha} \tau \alpha$ เ. Obgleich von Strabon ( VII 5,3) zu den Pannoniern gezählt, zeigt sich bei den Daesitiaten und bei anderen Völkern in den Dinariden durch ihre materielle Kultur und Onomastik eine sehr nahe Verwandtschaft zur illyrischen Welt. ${ }^{53}$ Aus diesem Grund wird neben der Einteilung der Bevölkerung des vorrömischen Illyricum in Histrier, Liburner, Japoden, Delmater, Illyrer und Pannonier eine weitere sogenannte „dalmatisch-pannonische“ oder „ostdalmatische“ Gruppe diskutiert. ${ }^{54}$

Im Vergleich zu anderen Völkern, die den Pannoniern zugeschrieben werden, ist die Ausdehnung des daesitiatischen Gebietes nach A. DOMIĆ KUNIĆ ${ }^{55}$ relativ gut bekannt. Der Urbanus bildet demzufolge die Grenze im Westen gegenüber den Mäzäern und an seinem Oberlauf gegenüber den Delmatern. Während im Nordosten der Gebirgszug der Majevica den daesitiatischen Siedlungsraum von dem der Skordisker trennte, bildete der Dreinos (Drina) die Grenze nach Osten, an dessen Oberlauf der daesitiatische Raum an denjenigen der Pirusten grenzte. Die südliche Grenze ist nicht gesichert. Nach A. DoMIĆ KUNIĆ ${ }^{56}$ wird diese beim Gebirge liegen, in welchem sich die Quellgebiete des Naron (Neretva), Bathinus / Basanius (Bosna) und Dreinos (Drina) finden. Während die bronze- und eisenzeitliche Glasinac-Kultur dem archäologischen Befund nach im Gebiet des heutigen Ostbosnien ab dem 3. Jh. v. Chr. nicht mehr zu fassen ist, haben die später in antiken Quellen bekannten Daisitiaten demnach wohl eine Verbreitung nach Osten bis zur Drina erfahren. ${ }^{57}$

Archäologische Ausgrabungen erfassten bisher ausschließlich Nekropolen. Dennoch konnten 120 Gradina-Anlagen im gebirgigen und mit Wäldern durchzogenen Land der Daesitiaten lokalisiert werden. ${ }^{58}$ Ähnlich den der Adriaküste näher gelegenen Gemeinwesen, kann aufgrund der Vielzahl von größeren und kleineren ständig besiedelten Höhensiedlungen sowie mehrerer, als Wallburgen erkannter Gradinen, eine hierarchisch gegliederte Struktur festgestellt werden. Der Hauptort dieses Bündnisses verschiedener Gemeinwesen ist inschriftlich bezeugt. Es handelt sich hierbei um die noch nicht erforschte Gradina-Anlage im heutigen Breza, nordöstlich von Sarajevo, welche einer römischen Inschrift zufolge als H(edum) $\mathrm{C}$ (astellum) D(a)esitiatum überliefert ist. ${ }^{59}$

Im Gebiet der späteren civitas Daesitiatum kann man sich mit Blick auf die Infrastruktur zumindest von einer Gradina-Anlage ein Bild machen. Es handelt sich dabei um die Siedlung in Pod bei Bugojono in Zentralbosnien, welche von der mittleren Bronzezeit bis in die späte Eisenzeit hinein besiedelt war. Das zum Teil freigelegte Areal brachte eine regelmäßige Anordnung von Straßen und Gebäuden zum Vorschein, welche bis ins 12 . Jh. v. Chr. zurückreicht. ${ }^{60}$ Des Weiteren lässt der

\footnotetext{
${ }^{52}$ DOMIĆ KUNIĆ 2006, 82, Anm. 95.

${ }^{53}$ DOMIĆ KUNIĆ 2006, 83.

${ }^{54}$ DŽINO 2005, 48.

${ }^{55}$ DOMIĆ KUNIĆ 2006, 83.

${ }^{56}$ DOMIĆ KUNIĆ 2006, 82.

${ }^{57}$ SANADER 2009, 17.

${ }^{58}$ DOMIĆ KUNIĆ 2006, 82.

${ }^{59}$ PAŠKVALIN 200, 522.

${ }^{60}$ WILKES 1992, 50.
} 
Befund zwei sich im rechten Winkel kreuzende Hauptstraßen erkennen, welche einen Umbau im 6. Jh. v. Chr. erfuhren. Es handelt sich dabei um die Abtragung eines am Kreuzungspunkt der beiden Achsen liegenden Gebäudes, wodurch sich ein offenes Zentrum ergab. Zudem sind nach Ausweis der Funde verschiedene Werkstätten auszumachen, welche der Siedlung, obgleich von kleiner Dimension $(150 \times 100$ m), einen ausgesprochen urbanen Charakter verleihen. Südlich des Hügels wuchs im Laufe der Zeit eine mehrere tausend Quadratmeter einnehmende suburbane Siedlung heran, welche nach Aufgabe des Burgberges in römischer Zeit die vorrangige Stellung besaß. $^{61}$

Außer dem oben genannten Beispiel ist bislang nur sehr wenig über die Siedlungen dieser seit der späten Bronzezeit den „Daesitiaten“ zugeschriebenen sogenannten „Mittelbosnischen Kultur“62 bekannt.

Das Gebiet des heutigen Mittelbosnien galt seit dem Neolithikum als Kontaktzone zwischen den Kulturen am Adriatischen Meer und dem Donauraum. Mykenische Keramik auf Höhensiedlungen im bosnischen Erzgebirge geben Belege für direkte oder indirekte Beziehungen zur ägäischen Welt während der Bronzezeit. Funde von Bernstein mit Ritzungen etruskischer Buchstaben sowie Keramikfragmente mit oskisch-umbrischer Schrift geben Auskunft über Kontakte zu den archaischen Kulturen Mittelitaliens. ${ }^{63}$ Am häufigsten treten jedoch Kunstobjekte aus der sogenannten ,graeco-illyrischen Kultur “64 von der Mitte des 6. Jhs. v. Chr. bis zum Anfang des 5. Jhs. v. Chr. auf, und zwar nicht nur im Dinarischen Gebirge. Vielmehr fanden diese kostbaren Gegenstände, zumeist korinthischer und attischer sowie ionischer Provenienz, ihre Verbreitung in den Gebieten westlich der Flüsse Axios (Vardar) und Margus (Morava). Dieser Umstand legt die Vermutung nahe, dass ein Kulturtransfer von Süden nach Norden entlang der großen Flussläufe stattfand. Die Funde aus dem Glasinac-Komplex im östlichen Bosnien hingegen belegen einen vom westlichen Schwarzmeergebiet über die Donau und Sava führenden Transfer.

\section{Illyrien}

Die „Illyrer im engeren Sinn“ (Kulturgruppe Glasinac-Mati ${ }^{65}$ bzw. GlasinacBurrel $^{66}$ ) setzen sich aus verschiedenen Gemeinwesen entlang der Ostküste der südlichen Adria und des Hinterlandes des Dinarischen Gebirges zusammen (z.B. Autariaten, Ardiäer, Daorser, Pirusten, Labeaten). Diese zwischen den Flussebenen des Naron (Neretva), Savus (Sava), Istros (Donau), Margus (Morava) und Mathis (Mati) gelegene Landschaft ist eine sehr gebirgige, wald- und erzreiche Region. Die Hochebene von Glasinac im heutigen Ostbosnien ist aufgrund der reichhaltigen Denkmäler (Gradina-Anlagen, Grabtumuli, Bronze- und Eisenwaren) als Kerngebiet der bronze- sowie eisenzeitlichen illyrischen Kultur interpretiert worden. ${ }^{67}$ Die bislang gezählten und dokumentierten 47 Gradina-Anlagen allein im Glasinacer Gebiet heben sich durch ihre vermehrt vorkommenden geometrischen Formen sowie

\footnotetext{
${ }^{61}$ ČOVIĆ $1975,121-129$.

${ }^{62}$ Vgl. ČOVIĆ 1987b, 481-530.

${ }^{63} \mathrm{Ob}$ die wenigen Objekte auf dem Wasserweg über das Adriatische Meer oder auf dem Landweg über die traditionelle Ost-West-Verbindung durch das pannonische Zweistromland in die „mittelbosnischen“ Gemeinwesen Einzug fanden, scheint bislang nicht geklärt zu sein.

${ }^{64}$ WILKES 1992, 104-109.

${ }^{65}$ Vgl. ANDREA 1985, 163-174; ČOVIĆ 1987c, 575-643.

${ }^{66}$ Vgl. PARZINGER 1991, 205-261.

${ }^{67}$ PARZINGER 1991, 205-261.
} 
in ihrer Anordnung in Form eines gleichschenkligen Dreiecks von anderen Anlagen auf dem Westbalkan ab. ${ }^{68}$

Daneben gehört ein weiteres bekanntes Bauwerk aus prähistorischer sowie antiker Zeit dem ostadriatischen Raum an. Die Rede ist von der Anlage der „Gomila“. Hierbei handelt es sich im wesentlichen um künstlich errichtete Hügel, welche die bronzezeitliche Tradition der Bestattung unter Grabhügeln fortführten. Wie bereits M. KORKUTI $^{69}$ zusammenfassend darstellte, wurden die Tumuli in der Herzegowina, in Dalmatien und in Montenegro ausschließlich aus Stein errichtet, während diese auf dem Gebiet des heutigen Albanien zumeist aus Erde bestehen. Die aus sorgfältig zusammengefügten und verfüllten Steinkreisen mit kuppelförmigen Abdeckungen gefertigten Gomilen sind darüber hinaus in Liburnien, Japodien und im gesamten Glasinac-Gebiet verbreitet. Das archäologische Bild von Tausenden von Gradinen kann des Weiteren mit Zehntausenden von Gomila genannten Tumuli vervollständigt werden. Doch liegen hierfür keine konkreten Zahlen vor. Alleine der Bezirk Rogatica im östlichen Bosnien, welcher von M. HOERNES ${ }^{70}$ als „Riesenfriedhof“ bezeichnet wurde, weist seinen Schätzungen zufolge 20.000 Tumuli auf.

Während die ober- und mitteladriatischen Gruppen jeweils als ausgereifte Kulturen erst seit dem 12.-9. Jh. v. Chr. archäologisch zu fassen sind, ist dies im Bereich des Glasinac sowie im nördlichen Mati-Tal bereits um 1400 v. Chr. der Fall. ${ }^{71}$

Eine territoriale Transformation ist nach antiken Quellen demnach auch in Illyrien zu konstatieren. Erscheinen in den Quellen aus archaischer Zeit (Hekataios, FGrH 8; Herodot IV 49) die Illyrer als ein einzelnes Ethnos, so geben die klassischen (Thukydides I 24,1; Pseudo-Skylax, Periegesis 21-27), hellenistischen (PseudoSkymnos 415-422; Polybios XXXII 18) und römerzeitlichen (Livius XLV 26, 13-15; Strabon VII 5,3; Appian, Illyr. 1-2) Autoren über Bündnisse sowie Königreiche Auskunft. Neben den Autariaten im Landesinneren, werden die Ardiäer demnach als bedeutendste Macht am und im Adriatischen Meer genannt.

Das vom 5. / 4. bis 2. Jh. v. Chr. bestehende und in verschiedenen Zeiten jeweils mit Taulantern, Ardiäern bzw. Labeaten gleichzusetzende Illyrische Königreich (Abb. 2.) erstreckte sich zur Zeit seiner größten Ausdehnung im Nordwesten bis zur Insel Pharos sowie bis zu den Delmatern, welche sie eine Zeit lang beherrschten. ${ }^{72}$ Im Zeitalter des Hellenismus gehörten dem sehr einflussreichen Reich das südliche Illyricum, das griechische Epidamnos, Teile des Epeiros sowie die Insel Korfu an.

Während es nach Appian (Illyr. 9) im Land des Genthios 70 Poleis gab, sind als Hauptorte des Illyrischen Königreichs nach J. WILKES ${ }^{73}$ die Städte Lissos (Lëzha), Scodra (Shkodër) sowie Meteon (Medun) zu nennen. Nach ihrer Lage auf steil abfallenden Anhöhen sowie den Höhenlinien folgenden und durch Türme verstärkten Umfassungsmauern aus großen Steinblöcken zu urteilen, waren diese Städte in der Tat Residenzen und Festungen zugleich. Den Königen waren des Weiteren größere und kleinere Gemeinwesen unter Führung von lokalen Fürsten („Principes“) unterstellt. Letztere residierten ebenso in großen Höhensiedlungen von mehreren Hektar Fläche, welche genauso wie die „illyrischen Königsstädte“ mit der einheimischen Technik des Trockenmauerwerks befestigt und mit Türmen verstärkt

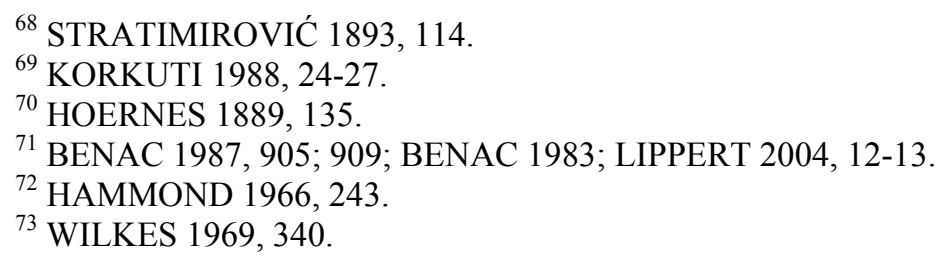


waren, nach J. WILKES ${ }^{74}$ jedoch weniger imposant sowie weniger griechischen Einflüssen ausgeliefert als die letztgenannten. Zu den sogenannten „Fürstenstädten“ werden die befestigten Höhensiedlungen im Hinterland des Ostufers des Skadarsko Jezero / Shkodër-Sees (z.B. Gajtani, Kodra Maršenjit, Kalaja Hotit, Kalaja Šamborit) zu zählen sein.

Ab dem Ende des 8. Jhs. v. Chr. sind sogenannte Fürstengräber belegt, welche für gesellschaftliche Eliten in einem jeweils bestimmten Gemeinwesen sprechen. Darüber hinaus unterhielten diese Gemeinwesen, den überaus reich ausgestatteten Gräbern nach zu urteilen, bereits in frühester Zeit rege Beziehungen sowohl zu verschiedenen griechischen Poleis der Adria, Ägäis und des Schwarzmeerraumes als auch zur etruskischen Welt Mittelitaliens.

\section{Südillyrien}

Nach H. PARZINGER ${ }^{75}$ bieten die Regionen des heutigen Mittelalbanien sowie Westmazedonien (Pelagonien) bis zum griechischen Kulturraum keine geschlossenen Fundumstände (außer Kuç i Zi und Trebenište), welche eine archäologische Kulturgruppe erkennen lassen würden. Aufgrund der in den antiken literarischen Quellen vertretenen Charakterisierung der in jener Region beheimateten Völker und Städte als ,illyrisch“, ist die Landschaft als „Südillyrien“ in die moderne Literatur eingegangen. ${ }^{76}$ Im Norden bildet der Mathis (Mati) demnach die Grenze zu den „Illyrern im engeren Sinn“ und im Osten trennt das Gebirge des Scardon Mons (Šar Planina) mit Gipfeln von bis zu 2747 Metern Höhe sowie die Seenlandschaft des Ohrid und Prespa Südillyrien von den Königreichen Dardanien, Paionien und Makedonien.

Während die Landschaft durch hohe Gebirge nach außen abgeschlossen ist, verfügt sie bis heute insbesondere in den Küstengebieten sowie den flacheren Regionen im Landesinneren über ein ausgesprochen fruchtbares Land. Für die Bewohner Südillyriens bildete nach M. KORKUTI ${ }^{77}$ die artenreiche und intensive Landwirtschaft zusammen mit der Viehzucht im gebirgigen Landesinneren die Basis der Wirtschaft. Zudem ist für die erzreichen Gebiete eine intensive Verhüttung sowie fortschrittliche Verarbeitungstechnik in der Metallproduktion vor allem im Zeitraum vom 7. bis 5. Jh. v. Chr. nachgewiesen. Aufgrund der günstigen geographischen Lage zwischen mediterraner Welt und Mitteleuropa und der engen Kontakte zu den Nachbargebieten des restlichen Illyricum, Mitteleuropa, Thrakien, Makedonien, Süditalien sowie Griechenland blühte der Handel und somit der Reichtum dieser antiken Landschaft auf.

Wie M. KORKUTI ${ }^{78}$ erkannte, hatte die Entstehung neuer sozialer Schichten zum Schutz des damit verbundenen Wohlstands gegen Ende des 7. Jhs. v. Chr. „regelrechte politische Stammesbündnisse“ mit einem Basileus an der Spitze zur Folge. Neben den Bündnissen bei Taulantern und Encheleern, wurden im 6. und 5. Jh. v. Chr. ähnliche Bündnisse von den sich östlich anschließenden "thrako-illyrischen" Völkern der Dardaner und Paionier gebildet. Des Weiteren erkannte N. CEKA ${ }^{79}$, dass sich sowohl im Epeiros als auch in Südillyrien ab dem 7. Jh. v. Chr. aus ursprünglich kleineren Wallburgen durch den Zusammenschluss von Kaufleuten und Handwerkern

\footnotetext{
${ }^{74}$ Siehe Anm. 73.

${ }^{75}$ PARZINGER 1991, 233.

${ }^{76}$ CEKA 1988, 215.

${ }^{77}$ KORKUTI 1988, 30.

${ }^{78}$ KORKUTI 1988, 31.

${ }^{79}$ CEKA 1988, 38.
} 
sowie intensiven Handelsbeziehungen neue Städtebaukonzepte ergaben (z.B. Buthroton, Treport, Mashkjeza, Margëlliç, Dorëz). Diese unterscheiden sich sowohl in ihrer Größe als auch durch die Art der Steinbearbeitung von den Wallburgen der einsetzenden Eisenzeit: „Es handelt sich jeweils um kleine Siedlungen auf 0,5 bis 8 ha großen Flächen, als viele Befestigungen der Bronze- und frühen Eisenzeit schon zwischen 9 und 20 ha groß waren, die eigentlichen Städte des 5. - 1. Jh. v. Chr. aber zwischen 10 und 30 ha umfassen". ${ }^{80}$ Einige derartige Zentren entlang der gesamten Ostküste der Adria werden bereits für das 6. Jh. v. Chr. von Hekataios von Milet (FGrH 8) in seinem Werk „Europa“ genannt, über deren Infrastruktur aufgrund fehlender Grabungen jedoch kaum etwas bekannt ist.

Nach N. CEKA ${ }^{81}$ liegt sowohl den epeirotischen als auch den illyrischen Städten eine von der Mitte des 7. Jhs. v. Chr. bis zur Mitte des 5. Jhs. v. Chr. andauernde protourbane Phase zugrunde. Diese habe sich gegenüber den „Stammessiedlungen“ der Eisenzeit durch die Entstehung neuer Typen von Wehranlagen unterschieden und bereits im 6. Jh. v. Chr. ihre Verbreitung bis in die nördlichste Zone der Liburner sowie bis in die östlichste Zone von Dardanien und Paionien erreicht.

Im Vergleich zu den bereits in der Bronzezeit angelegten Befestigungsanlagen an Höhensiedlungen in anderen ostadriatischen Gemeinwesen (z.B. Monkodonja, Škrip, Debelo brdo) erscheinen diejenigen im südlichen Illyrien nach J. WILKES ${ }^{82}$ dagegen erst im 5. Jh. v. Chr. Es handelt sich dabei um Siedlungen mit einer Fläche von vier bis fünf Hektar. Die in der Regel knapp 3,50 Meter starken Umfassungsmauern sind jeweils aus zwei Reihen unbearbeiteten großen Steinblöcken errichtet, deren Innenraum mit kleineren Steinen aufgefüllt ist. Derartig befestigte Siedlungen besitzen in dieser frühen Phase keine Türme und nur ein oder zwei Tore (z.B. Gajtan, Tren, Ventrok, Ganjolle, Scodra, Marshej, Lissos Phase I und II, Zgërdesh Phase I, Daorson Phase I und II).

Um die Mitte des 5. Jhs. v. Chr. bekommen die vormals protourbanen Zentren der Gemeinwesen der Amantier und der Byllionen ihren Stadtmauern nach zu urteilen urbane Strukturen. Nach Vorbild des griechischen Kolvóv sollen politische Einheiten mit Amantia und Byllis als Zentralorten entstanden sein. ${ }^{83}$

Durch die Expansionspolitik Dionysios' I. von Syrakus erscheinen im ionischen und adriatischen Raum im beginnenden 4. Jh. v. Chr. neue planmäßig errichtete Stadtanlagen (Kassope, Phoinike, Issa, Pharos). Nach dem Muster dieser Anlagen sind in der ersten Hälfte des 4. Jhs. v. Chr. im unteren Tal des Aoos (Vjosë) demnach Olympe bei den Amantiern und die Siedlung im heutigen Gurzeza bei den Byllionen entstanden. Wie bereits N. CEKA ${ }^{84}$ erkannte, unterscheidet diese Städte von den früheren illyrischen und epeirotischen Siedlungen eine besonders ausgesparte Fläche für gesellschaftliche Aktivitäten (ähnlich wie die Agora in der griechischen Polis), die Lage auf dem Südhang eines Hügels, der nahezu viereckige Grundriss sowie eine Umfassung aus polygonalem Mauerwerk.

In der Mitte des 4. Jhs. v. Chr. begann in Südillyrien eine zweite Phase des Städtebaus. Nur zwei Kilometer westlich des alten Zentrums der Byllionen entstand die neue Hauptstadt mit Namen Byllis. Der ehemalige Hauptort wurde später Nikaia genannt. Das neue Byllis wurde gemäß der Tradition der Gradina-Kultur auf dem

\footnotetext{
${ }^{80}$ KORKUTI 1988, 38.

${ }^{81}$ CEKA 1988, 215.

${ }^{82}$ WILKES 1992, 129-130.

${ }^{83}$ CEKA 1988, 217-219.

${ }^{84}$ CEKA 1988, 221, 225.
} 
Plateau eines Hügels errichtete und mit einer Mauer umfasst. Das Plateau liegt 524 Meter über dem Meeresspiegel und die 2200 Meter langen Mauern umschließen eine Fläche von etwa 30 ha. In der zweiten Hälfte des 4. Jhs. v. Chr. wurde auch Scodra in der epirotischen Technik der moenia aeacia befestigt. Entfernt vom Küstenland der südlichen Adria, erscheinen in den östlichen Gebieten Dassaretiens, südlich des Prespa-Sees, neben Pelion mehrere Städte sowie Wallburgen im Raum des heutigen Pogradec und Korça. Nach N. CEKA ${ }^{85}$ übten die griechischen Kolonien Apollonia und Dyrrhachion nur eine geringe Vorbildfunktion aus, so dass im Zuge der Bautätigkeit die illyrischen sowie epirotischen Erfahrungen wohl die Hauptrolle gespielt haben dürften.

Was N. CEKA ${ }^{86}$ für den Prozess der Urbanisierung in der protourbanen Phase sowohl für Südillyrien als auch Epeiros für die vorhellenistische Zeit diagnostiziert hat, lässt sich nach dem bislang erarbeiteten Kenntnisstand auf das gesamte Gebiet des vorrömischen Illyricum übertragen. Demnach geht dem Städtebau eine frühe Urbanisierung voraus, für die zwei Faktoren entscheidend sind: Zum einen lässt sich die Analyse der Befestigungen und zugleich auch ihre Genesis und ihre weitere Entwicklung archäologisch verfolgen. Zum anderen ist der wirtschaftliche Einfluss durch die korinthisch-korkyreischen Kolonien Epidamnos / Dyrrhachion und Apollonia in der südlichen Adria auf die protourbanen Siedlungen, die sich aber der monumentalen Architektur gegenüber gleichgültig verhielten, zu nennen. Diesem zweiten urbanisierenden Faktor in Bezug auf die Ostadriatische Antike sind für die spätklassische Epoche das syrakusanische Issa und das parische Pharos sowie Korkyra Melaina und Tragourion in der mittleren Adria hinzuzufügen.

Das im Hinterland der südlichen Adria gelegene Südillyrien gehört neben Liburnien nicht nur zu den am stärksten urbanisierten Gebieten, sondern ist aufgrund der geographischen Nähe zur griechischen Welt die bislang am intensivsten studierte Landschaft auf dem Westbalkan.

Ähnlich wie bei anderen Gemeinwesen an der Ostadria, ist auch hier eine hierarchisch gegliederte Siedlungsstruktur zu erkennen. Nach N. CEKA ${ }^{87}$ bestimmte die städtische Struktur auch ihren politischen Aufbau, welche aus Inschriften als Koıvóv bekannte politische Einheiten bildeten. Dabei handelt es sich „um einen Bund von Städten und Dörfern mit republikanischer Regierungsform und mit jedes Jahr neu

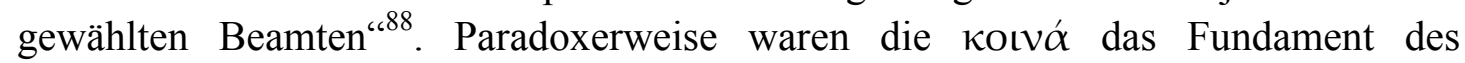
monarchischen Überbaus sowohl im illyrischen als auch im epeirotischen Königtum sowie später in der römischen Provinz bis zum augusteischen Prinzipat. Wie in anderen ostadriatischen Gemeinwesen, bildete die größte Stadt das wirtschaftliche, politische und religiöse Zentrum des jeweiligen Koinon.

\section{Schlussbetrachtung}

Die geographische Lage zwischen mediterranen Hochkulturen einerseits und den Kulturen im kontinentalen Mitteleuropa andererseits begünstigte wohl zusammen mit den reichen Erzvorkommen im Dinarischen Gebirge und den dadurch entstehenden weitreichenden Kontakten demnach bereits sehr früh die eigene kulturelle Entwicklung. Obgleich nicht alle Gradinen zur selben Zeit bewohnt waren, bestimmten doch die meisten Anlagen von der geometrischen Epoche bis zur

\footnotetext{
${ }^{85}$ CEKA 1988, 51-54.

${ }^{86}$ CEKA 1988, 215-217.

${ }^{87}$ CEKA 1988, 224.

${ }^{88}$ Siehe Anm. 87.
} 
römischen Eroberung das Bild der verschiedenen antiken Landschaften auf dem Westbalkan. Während Histrien die am dichtesten besiedelte Landschaft an der Ostadria darstellt, so bilden Liburnien sowie Südillyrien die am meisten urbanisierten Regionen jener Küstenlandschaft. Dagegen kann aufgrund mangelnder Forschungen bezüglich der Topographie sowie der Infrastruktur einzelner Siedlungen in den im Dinarischen Gebirge gelegenen Japodien, Ostdalmatien und Illyrien nur wenig ausgesagt werden. Die bislang in den bekannten Städten der mittelgebirgs- bis alpinen Region im Hinterland des Adriatischen Meeres getätigten Funde belegen seit den frühesten Zeiten zumindest komplex gegliederte Siedlungsstrukturen sowie hoch entwickelte Organisationsformen.

Im Unterschied zu den frühen italischen Bewohnern am Adriatischen Meer gehören vielmehr die Histrier, Liburner sowie Illyrer zu den seefahrenden Völkern in diesen Gewässern. Entgegen ihrer in den antiken Quellen politisch motivierten Zuschreibung als „gefürchtete Seeräuber“, fungierten die an der Ostadria beheimateten ,illyrischen“ Völker wohl als Kulturvermittler.

Der wirtschaftliche Aufschwung führte in Südillyrien am Ende des 7. Jhs. v. Chr. (Königreiche der Taulanter, Encheleer) und im 5. Jh. (Koinon der Amantier, Byllionen), in Illyrien ab dem 5. Jh. (Königreich der Illyrer / Ardiäer / Labeaten), in Liburnien im 5. / 4. Jh. (Liburnische Liga), in Histrien im 3. / 2. Jh. (Königreich der Histrier) sowie im Dinarischen Hinterland ab dem 3. Jh. (Cisalpines Japodien, Transalpines Japodien, Delmatischer Bund, Maezaeischer Bund, Ditionischer Bund, Daesitiatischer Bund) $\mathrm{zu}$ einer weiteren territorialen und damit sozialen Transformation. Demnach ist die politische Situation auf dem antiken Westbalkan mit derjenigen im vorrömischen Italien und dem nördlichen Griechenland durchaus zu vergleichen.

Die verschiedenen durch terrassierte Hügel, angelegte Trockenmauern sowie errichtete Grabdenkmäler planmäßig umgestalteten bzw. neu angelegten Landschaften im Illyricum bilden somit bereits sehr früh eine im antiken Mittelmeerraum einzigartige und zugleich charakteristische Kulturlandschaft. 


\section{Verzeichnis der abgekürzt zitierten Literatur}

\section{ALFÖLDY 1965}

G. Alföldy, Bevölkerung und Gesellschaft der römischen Provinz Dalmatien (Budapest 1965).

\section{ANDREA 1985}

Z. Andrea, Mbi gjenezën dhe vijmësinë e kulturës së Matit në epokën e bronzit. A propos de la genèse et de la continuité de la culture de Mat à l'époque du bronze, in: Iliria 15,2, 1985, 163-174.

\section{BALEN-LETUNIĆ 2004}

D. Balen-Letunić, Japodi, The Iapodes, Die Japoden, in: A. Rendić-Miočević (Hrsg.), Ratnici na razmeđu istoka i zapada (Zagreb 2004), 211-257.

\section{BATOVIĆ 1987}

S̆. Batović, Liburnska grupa, in: A. Benac - S. Gabrovec (Hrsg.), Praistorija BEKIĆ 1996 Jugoslavenskih Zemalja 5, Željezno doba (Sarajevo 1987), 339-390.

L. Bekić, Sustav gradina na rovinjskom području, in: Histria archaeologica 27, 1996, 19-92.

\section{BENAC 1983}

A. Benac (Hrsg.), Praistorija Jugoslavenskih Zemalja 4, Bronzano doba (Sarajevo 1983).

\section{BENAC 1987}

A. Benac - S. Gabrovec (Hrsg.), Praistorija Jugoslavenskih Zemalja 5, Željezno doba (Sarajevo 1987).

\section{BOARDMAN 1982}

J. Boardman, The prehistory of the Balkans; the Middle East and the Aegean world, tenth to eighth centuries B.C., in: Ders. (Hrsg.), The Cambridge

\section{CEKA 1988} Ancient History, III Par I (Cambridge 1982) 181-237.

N. Ceka, Städtebau in der vorrömischen Periode in Südillyrien, in: Akten des XIII internationalen Kongresses für klassische Archäologie. Berlin 1988 (Mainz 1990), 215-229; 488-490.

\section{CHAPMAN - SHIEL 1991}

J. Chapman - R. Shiel, Settlement, soils and societies in Dalmatia, in: G. Barker - J. Lloyd (Hrsg.), Roman landscapes. Archaeological survey in the

\section{ČAČE 1983-84} mediterranean region (London 1991), 62-75.

S. Čače, Truentum Liburnorum, in: Radovi. Razdio društvenih znanosti 10 (1983-84), 7-16.

\section{ČAČE 1987/88}

S. Čače, Položaj rijeke Telavija I pitanje japodskog primorja - The position of the river Telavium and the question of Japod coastal part, in: Radovi 27,

\section{ČARGO 2004} 1987/88, 65-92.

\section{ČOVIĆ 1975}

B. Čargo, Issa. A historical and archaeological guide (Split - Vis 2004).

B. Čović, Pod bei Bugojno. Eine befestigte Siedlung der Bronze- und Eisenzeit in Zentralbosnien, in: A. Benac (Hrsg.), Utvrđena ilirska naselja. Međunarodni kolokvij, Mostar 24-26 oktobar 1974 - Agglomérations fortifiées 
illyriennes. Colloque international, Mostar 24-26 octobre 1974 (Sarajevo 1975), 121-129.

\section{ČOVIĆ 1976}

B. Čović, Od Butmira do Ilira (Sarajevo 1976).

\section{ČOVIĆ 1987a}

B. Čović, Srednjodalmatinska grupa, in: A. Benac - S. Gabrovec (Hrsg.),

Praistorija Jugoslavenskih Zemalja 5 (Sarajevo 1987), 442-480.

\section{ČOVIĆ 1987b}

B. Čović, Srednjobosanska grupa, in: A. Benac - S. Gabrovec (Hrsg.),

\section{ČOVIĆ 1987c}

Praistorija Jugoslavenskih Zemalja 5 (Sarajevo 1987), 481-530.

B. Čović, Glasinačka kultura, in: A. Benac - S. Gabrovec (Hrsg..), Praistorija Jugoslavenskih Zemalja 5 (Sarajevo 1987), 575-643.

\section{DOMIĆ KUNIĆ 2006}

A. Domić Kunić, Posljedna faza osvajanje Južne Panonije, in: VAMZ, 3.s., XXXIX (2006) 59-164.

\section{DRECHSLER-BIŽIĆ 1987}

R. Drechsler-Bižić, Japodska grupa, in: A. Benac - S. Gabrovec (Hrsg.), Praistorija Jugoslavenskih Zemalja 5 (Sarajevo 1987), 391-441.

\section{DULAR - TECCO HVALA 2007}

J. Dular - S. Tecco Hvala, Southeastern Slovenia in the early iron age.

\section{DŽINO 2005}

Settlement - Economy - Society (Ljubljana 2007).

D. Džino, Illyrian policy of Rome in the late Republic and early Principate (Adelaide 2005).

\section{GABROVEC 1987a}

S. Gabrovec, Notranjska Grupa, in: A. Benac - S. Gabrovec (Hrsg.), Praistorija Jugoslavenskih Zemalja 5, Željezno doba (Sarajevo 1987), 151-177.

\section{GABROVEC 1987b}

S. Gabrovec, Svetolucijska grupa, in: A. Benac - S. Gabrovec (Hrsg.), Praistorija Jugoslavenskih Zemalja 5, Željezno doba (Sarajevo 1987), 120-150.

\section{GABROVEC 1987c}

S. Gabrovec, Dolenjska grupa, in: A. Benac - S. Gabrovec (Hrsg.), Praistorija Jugoslavenskih Zemalja 5, Željezno doba (Sarajevo 1987), 29-119.

\section{GABROVEC - MIHOVILIĆ 1987}

S. Gabrovec, K. Mihovilić, Istarska Grupa, in: A. Benac - S. Gabrovec (Hrsg.), Praistorija Jugoslavenskih Zemalja 5, Željezno doba (Sarajevo 1987), 293-338.

\section{GAFFNEY 2001}

V. Gaffney, u.a., Enclosure and Defence: the Context of Mycenaean Contact with Central Dalmatia, in: V. Karagheorghis, C.E. Morris (Hrsg.), Defensive Settlements of the Aegean and the Eastern Meditteranean after c. 1200 B.C. (Nicosia 2001), 137-156.

\section{GIRARDI-JURKIĆ 1988}

V. Girardi-Jurkić, Histri i Etruščani - Histrians and Etruscans (Pula 1988).

\section{GLAVIČIĆ - MILETIĆ 2008}

M. Glavičić - Ž. Miletić, Critical approach to the exhibitions of the imperial cult in the Roman Illyricum with regard to its early stage of development, in: N. Marchetti - I. Thuesen (Hrsg.), Archaia, Case studies on research planning, 
characterisation, conservation and management of archaeological sites, BAR 1877 (Oxford 2008), 417-426.

\section{HAMMOND 1966}

N. Hammond, The Kingdoms in Illyria circa 400-167 BC, in: Annual of the British School at Athens 61, 1966, 239-53.

\section{HOERNES 1889}

M. Hoernes, Grabhügelfunde von Glasinac in Bosnien, in: Mitt. Anthr. Ges. Wien 19, 1889, 135.

\section{KIRIGIN 2003}

B. Kirigin, Greek civilization, in: E. Marin (Hrsg.), Archaeological Museum Split. Guide (Split 2003), 27-29.

\section{KIRIGIN 2008}

B. Kirigin, Grčko-helenistička zbirka u stalnom postavu Arheološkog muzeja $\mathrm{u}$ splitu - The Greek and Hellenistic Collection onm Exhibit in the Archaeological Museum in Split (Split 2008).

\section{KORKUTI 1988}

M. Korkuti, Illyrien in der Vorgeschichte, in: A. Eggebrecht (Hrsg.), Albanien, Schätze im Land der Skipetaren (Mainz 1988), 7-31.

\section{KUNTIĆ MAKVIĆ 2007}

B. Kuntić Makvić u.a., Die Illyrer, Zwischen Griechenland und Italien, in: M.

\section{LIPPERT 2004}

Sanader (Hrsg.), Kroatien in der Antike (Mainz 2007), 20-36.

A. Lippert, Das archäologische Bild der frühen Illyrer, in: G. Urso (Hrsg.), Dall'Adriatico al Danubio. L'Illirico nell'età greca e romana. Atti del convegno internazionale Cividale del Friuli, 25-27 settembre 2003 (Pisa 2004), 11-21.

\section{MARCHESETTI 1983}

C. Marchesetti, I castellieri preistorici di Trieste e della regione Giulia (Trieste 1903, reprint 1983).

\section{MIHOVILIĆ 2005a}

K. Mihovilić, Baumeister und Herrschaftseliten, Bronzezeit, in: Ž. Ujčić (Hrsg.), Histria, Istra, Istrien. Ein archäologisches Juwel in der Adria (Zagreb 2005), 31-36.

\section{MIHOVILIĆ 2005b}

K. Mihovilić, Histri - die Istrier und ihre Seemacht in der nördlichen Adria, Eisenzeit, in: Ž. Ujčić (Hrsg.), Histria, Istra, Istrien. Ein archäologisches Juwel in der Adria (Zagreb 2005), 37-48.

\section{MILIČEVIĆ BRADAČ 2007}

M. Miličević Bradač, Die Griechen in Kroatien, in: M. Sanader (Hrsg.), Kroatien in der Antike (Mainz 2007), 37-60.

\section{MLEKUŽ 2007}

D. Mlekuž, Who were the Cyclopes? Odyssey and Neolithic, Eneolithic and Bronze Age pastoralists from the east Adriatic coast and Dinarides, in: Situla 46, 2007, 1-14.

\section{OLUJIĆ 2007}

B. Olujić, Povijest Japoda (Zagreb 2007).

\section{PARZINGER 1991}

H. Parzinger, Archäologisches zur Frage der Illyrer, in: BRGK 72, 1991, 205261. 
Frankfurter elektronische Rundschau zur Altertumskunde 11 (2010)

SANADER 2009

M. Sanader, Dalmatia, Eine römische Provinz an der Adria (Mainz 2009) 1319.

SEMI 1991

F. Semi, Istria e Dalmazia - Uomini e tempi (Udine 1991).

SERGEJEVSKIJ 1931

D. Sergejevskij, Rimski spomenici iz Livna i Prekaje, in: GZM 43, 1931, 1923.

STARAC 1999

STARAC 2000

A. Starac, Rimsko vladanje u Histriji i Liburniji I (Pula 1999).

A. Starac, Rimsko vladanje u Histriji i Liburniji II (Pula 2000).

STRATIMIROVIĆ

G. Stratimirović, Ausgrabungen auf der Hochebene von Glasinac im Jahre SUIĆ 1968 1891, in: WMBH 1, 1893, 113-125.

SUIĆ 1981

M. Suić, Nin: problemi arheoloških istraživanja (Zadar 1968).

M. Suić, Zadar u starom vijeku (Zadar 1981).

ŠKEGRO 1999-2000

A. Škegro, Dalmion / Delmion i Delminium, kontroverze i činjenice, in: Opusc. archaeol. 23-24, 1999-2000, 395-403.

ŠKEGRO 2000

A. Škegro, Bergbau der römischen Provinz Dalmatiens, in: Godišnjak Centra za balkanološka ispitivanja Akademije nauka i umjetnosti Bosne i Hercegovine XXXI / 29, 2000, 53-176.

WILKES 1992

J. Wilkes, The Illyrians (Oxford 1992).

\section{Abbildungsverzeichnis}

Abb. 1. M. Šašel Kos, Appian and Illyricum (Ljubljana 2003), 186, Fig. 46.

Abb. 2. M. Šašel Kos, Appian and Illyricum (Ljubljana 2003), 224, Fig. 49.

Anto Pavic M.A.

Institut für Klassische Archäologie

Johannes Gutenberg-Universität

Jakob-Welder-Weg 18

D-55128 Mainz 
Frankfurter elektronische Rundschau zur Altertumskunde 11 (2010)

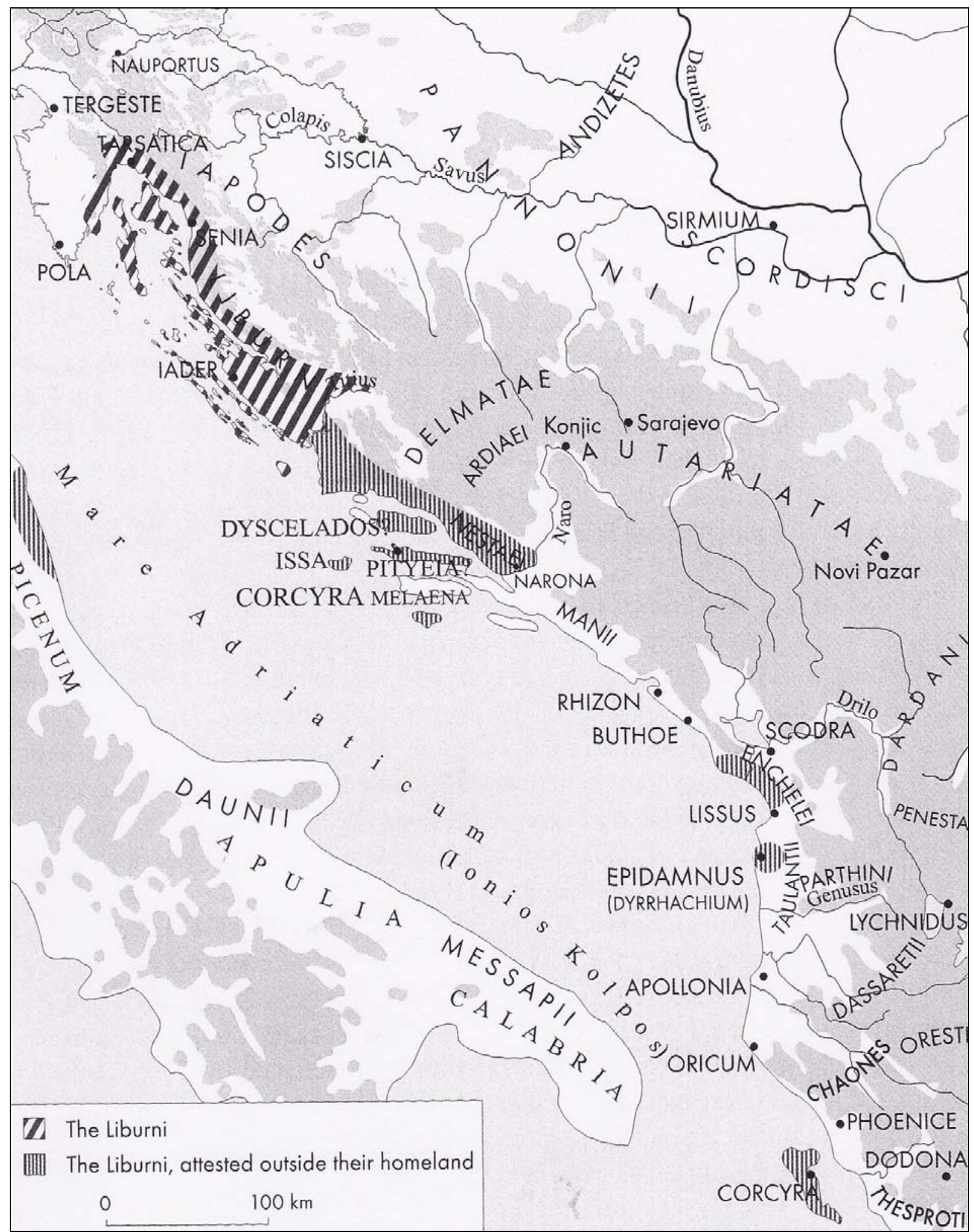

Abb. 1. Liburnische Thalassokratie im Adriatischen und Ionischen Meer nach antiken Quellen, 8.-4. Jh. v. Chr. 


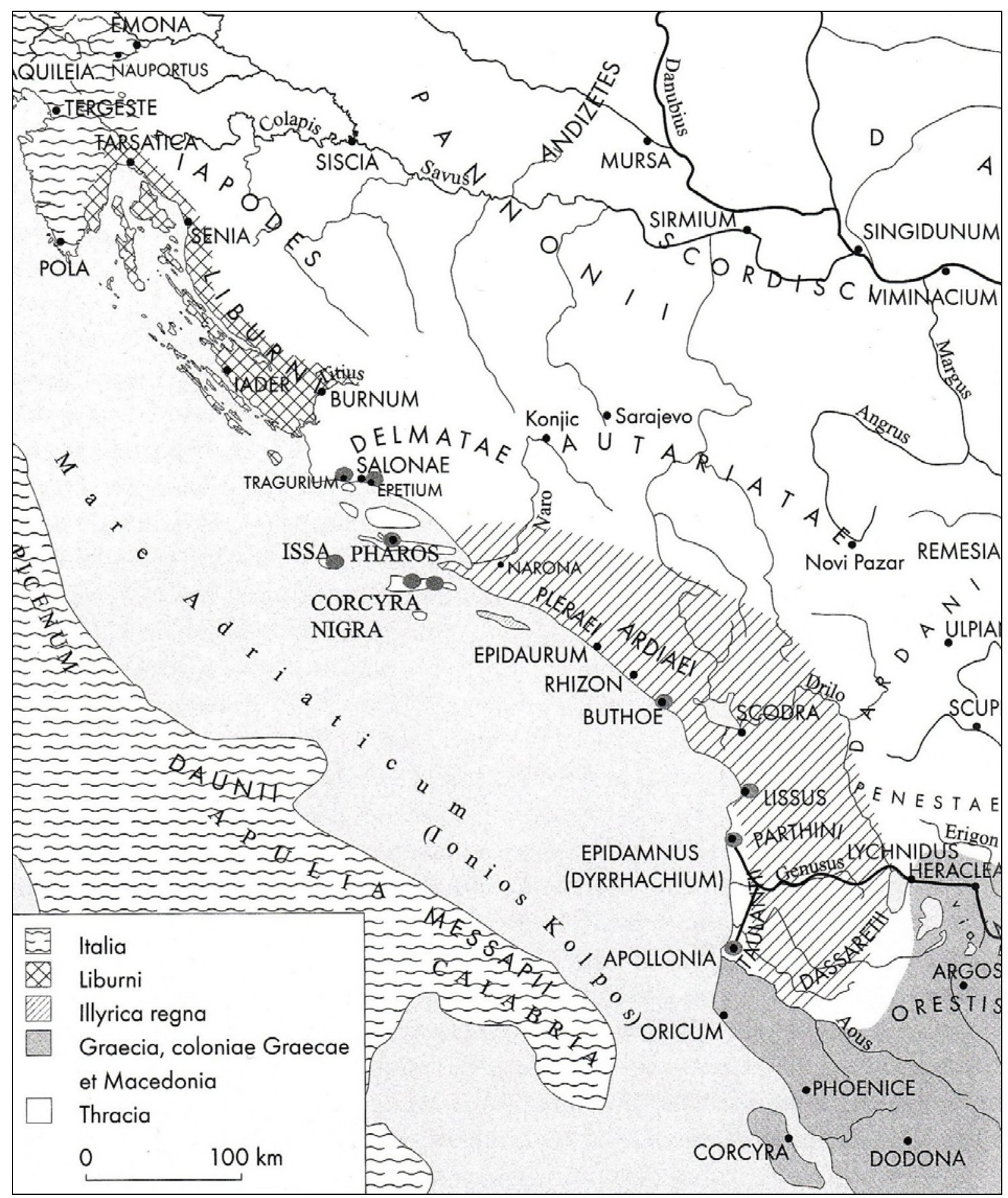

Abb. 2. Politische Situation auf dem Westbalkan nach 177. v. Chr.: Liburnische Liga, Illyrisches Königreich und andere Bündnisse 